\title{
Article \\ Thermal Conductivity of As-Cast and Annealed Mg-RE Binary Alloys
}

\author{
Huiyun Guo ${ }^{1}$, Shuhong Liu ${ }^{1} * \mathbb{C}^{\mathbb{D}}$, Lei Huang ${ }^{1}$, Deqing Wang ${ }^{1}$, Yong Du ${ }^{1}$ and Mingqiang Chu ${ }^{2}$ \\ 1 National Key Laboratory of Science and Technology on High-Strength Structural Materials, Central South \\ University, Changsha 410083, China; guo_huiyun@outlook.com (H.G.); leihuang_1994@163.com (L.H.); \\ wdq_bgrimm@163.com (D.W.); yong-du@csu.edu.cn (Y.D.) \\ 2 Centre of Excellence for Advanced Materials, Songshan Lake, Dongguan 523808, China; \\ Mingqiang.chu@ceamat.com \\ * Correspondence: shhliu@csu.edu.cn; Tel.: +86-731-88877300; Fax: +86-731-88710855
}

Citation: Guo, H.; Liu, S.; Huang, L.; Wang, D.; Du, Y.; Chu, M. Thermal Conductivity of As-Cast and Annealed Mg-RE Binary Alloys. Metals 2021, 11, 554. https:// doi.org/10.3390/met11040554

Academic Editor: Marcello Cabibbo

Received: 25 February 2021

Accepted: 25 March 2021

Published: 29 March 2021

Publisher's Note: MDPI stays neutral with regard to jurisdictional claims in published maps and institutional affiliations.

Copyright: (c) 2021 by the authors. Licensee MDPI, Basel, Switzerland. This article is an open access article distributed under the terms and conditions of the Creative Commons Attribution (CC BY) license (https:// creativecommons.org/licenses/by/ $4.0 /)$.

\begin{abstract}
Thermal conductivity and phase identification of Mg-RE (Rare-Earth) alloy (Mg-La, Mg-Ce, $\mathrm{Mg}-\mathrm{Nd}, \mathrm{Mg}-\mathrm{Sm}$ ) in both as-cast and annealed states were investigated. The thermal conductivity was measured by the laser flash method in the composition range of $4 \mathrm{wt}$.\% to $12 \mathrm{wt}$ \% RE and the temperature range of $298 \mathrm{~K}$ to $673 \mathrm{~K}$. Results demonstrated that homogenization treatment can increase its thermal conductivity. The thermal conductivity increases with the increasing temperature in two states, which is inconsistent with the pure magnesium, and the thermal conductivity of Mg-RE alloys decreases with the alloy additions. Compared with the atomic radius, valence, and intermetallic compounds, the solid solubility of the above four RE elements in $\alpha$-Mg plays a vital role in the thermal conductivity of Mg-RE binary alloy. The reduction of thermal conductivity caused by the addition of $\mathrm{Nd}$ and $\mathrm{Sm}$, which show observable solid solubility in $\alpha-\mathrm{Mg}$, is significantly greater than the addition of $\mathrm{La}$ and Ce with negligible solid solubility in $\alpha-\mathrm{Mg}$.
\end{abstract}

Keywords: magnesium alloy; heat treatment; thermal conductivity; microstructure

\section{Introduction}

Magnesium alloys are promising materials in the automotive, electronic, and aviation field because of light weight, high specific strength, outstanding damping performance, and environmental protection [1-3]. Thermal conductivity is an important thermophysical properties, and it plays an essential role in the performance of alloy. High thermal conductivity of magnesium alloys provides fast heat conduction. It ensures that the temperature is evenly distributed, thus improving fatigue property and prolonging the service life [4-6]. Thermal conductivity is affected by solid solution atoms, second phases, temperature changes, and heat treatment [7-12]. Pan et al. [13] found that the influence on thermal conductivity of magnesium alloys for the six solute elements was $\mathrm{Zn}<\mathrm{Al}<\mathrm{Ca}<\mathrm{Sn}<\mathrm{Mn}<\mathrm{Zr}$.

Among different magnesium alloy types, Mg-RE (Rare-Earth) alloys have superior properties such as excellent creep properties, high strength, and heat and corrosion resistance [14-16]. In contrast, there are few studies on the thermal conductivity. Rudajewva et al. [4] measured the thermal conductivity of as-cast Mg-(3.2-19.0 wt.\%) Sc from $293 \mathrm{~K}$ to $573 \mathrm{~K}$, which has a negative correlation with Sc content, while it has a positive correlation with temperature. Zhong et al. [17] experimentally studied the effect on thermal conductivity that four elements added in magnesium in as-cast and as-solutionized states at $298 \mathrm{~K}$. The order is $\mathrm{Ce}<\mathrm{Nd}<\mathrm{Y}<\mathrm{Gd}$. Su et al. [18] reported the influence of three typical $\mathrm{Ce}, \mathrm{Sm}$, and $\mathrm{Y}$ elements on magnesium alloys for both as-cast and as-solutionized at 298 K. Peng et al. [19,20] proved that adding Ce would obviously increase the strength of alloys without reducing the thermal conductivity. From these reports, we can see that these available measurements on the thermal conductivity of $\mathrm{Mg}-\mathrm{RE}$ alloys are either in the as-cast state or at room temperature. 
In order to comprehensively study the effect of various factors on the thermal conductivity of pure magnesium and obtain $\mathrm{Mg}$-RE alloy with outstanding thermal conductivity, $\mathrm{Mg}-\mathrm{RE}(\mathrm{RE}=\mathrm{La}, \mathrm{Ce}, \mathrm{Nd}, \mathrm{Sm}$ ) alloys were experimentally investigated. According to the solid solubility of the above four elements in $\alpha-\mathrm{Mg}$, they were divided into two groups. Group one, including La and Ce, shows negligible solid solubility, while the other group, including $\mathrm{Nd}$ and $\mathrm{Sm}$, shows observable solid solubility. The effect of elements types, elements content, temperature, and homogenization treatment on the thermal conductivity of these four binary systems will be discussed in details.

\section{Experimental Procedure}

The nominal composition of $\mathrm{Mg}-\mathrm{RE}(\mathrm{RE}=\mathrm{La}, \mathrm{Ce}, \mathrm{Nd}, \mathrm{Sm})$ alloys was listed in Table 1; the samples were prepared with pure magnesium (99.99 wt.\%) and master alloys of Mg-12 wt.\% La, Mg-25 wt.\% Ce, Mg-20 wt.\% Nd as well as Mg-35 wt.\% Sm. Raw materials were placed in a graphite crucible, and the induction furnace was filled with high purity Ar to protect the raw materials from oxidation during the melting process. They were remelted many times to ensure the homogeneities of the samples, and then four alloy ingots were obtained. Each alloy ingot was cut into two disc-shaped samples with a diameter of $10 \mathrm{~mm}$ and a thickness of $3 \mathrm{~mm}$. One piece was directly used for as-cast research, and the other piece was sealed in an evacuated silica capsule under vacuum (1 Pa) to wait for subsequent homogenization heat treatment. Mg-RE alloys were homogenized annealed at $673 \mathrm{~K}$ for 30 days, then quenched in water. Chemical analysis was performed with an inductively coupled plasma analyzer (IRIS Advantage 1000), and the detected composition is shown in Table 1. Scanning electron microscopy (SEM) (Zeiss Sigma SEM, Germany) and X-ray diffraction (XRD) (Rigaku D max/2550 VB+X-ray diffractometer) were used to observe the microstructure of the as-cast and annealed alloys and analyze their phases.

Table 1. Compositions of Mg-RE binary alloys.

\begin{tabular}{cccc}
\hline $\begin{array}{c}\text { Nominal Composition } \\
\text { of Allys (wt.\%) }\end{array}$ & $\begin{array}{c}\text { Actual Composition of } \\
\text { RE (wt.\%) }\end{array}$ & $\begin{array}{c}\text { Actual Composition of } \\
\text { RE (at. \%) }\end{array}$ & Mg \\
\hline Mg-4La & 3.96 & 0.71 \\
Mg-6La & 5.78 & 1.04 \\
Mg-8La & 8.31 & 1.50 \\
Mg-10La & 10.10 & 1.82 \\
Mg-4Ce & 3.16 & 0.55 \\
Mg-6Ce & 4.68 & 0.82 & \\
Mg-10Ce & 7.57 & 1.32 & \\
Mg-12Ce & 9.43 & 1.65 & \\
Mg-4Nd & 3.56 & 0.61 & \\
Mg-6Nd & 5.37 & 0.91 & \\
Mg-8Nd & 7.29 & 1.24 \\
Mg-10Nd & 8.89 & 1.51 & \\
Mg-4Sm & 3.54 & 0.58 \\
Mg-6Sm & 5.31 & 0.88 \\
Mg-8Sm & 6.73 & 1.11 \\
Mg-10Sm & 9.33 & 1.54 \\
Mg-12Sm & 11.00 & 1.82 \\
\hline
\end{tabular}

The laser flash method (NETZSCH LFA 457 laser conductometer, ASTM E1461 Standard, Germany) was used to measure thermal diffusivities ( $\alpha$ ) of Mg-RE alloy samples from $298 \mathrm{~K}$ to $673 \mathrm{~K}$, and repeated more than three times. The density at $298 \mathrm{~K}$ of all alloys was obtained by the Archimedes method, and it was obtained by Equation (1) [21] above $298 \mathrm{~K}$ :

$$
\rho=\rho_{0}-0.156(\mathrm{~T}-298)
$$

where, $\rho_{0}\left(\mathrm{~kg} / \mathrm{m}^{3}\right)$ is the density at $298 \mathrm{~K}, \mathrm{~T}(\mathrm{~K})$ is the absolute temperature.

The specific heat capacity $\mathrm{Cp}(\mathrm{J} /(\mathrm{g} \times \mathrm{K}))$ can be calculated using the Neumann-Kopp rule [22-24] combined with thermodynamic database [25-29]. 
The thermal conductivity $\lambda(\mathrm{W} /(\mathrm{m} \times \mathrm{K}))$ was obtained by Equation (2) [30]:

$$
\lambda=\alpha \times \rho \times \mathrm{Cp}
$$

The error ranges for measurement of the density and thermal diffusivity are both estimated to be $\pm 3 \%$. The reliability of the heat capacity calculated based on the thermodynamic database is estimated to be less than $\pm 5 \%$. The total uncertainty for the thermal conductivity is believed to be less than $\pm 7.85 \%$.

\section{Results}

The phase diagrams of the Mg-RE ( $\mathrm{RE}=\mathrm{La}, \mathrm{Ce}, \mathrm{Nd}, \mathrm{Sm})$ systems calculated by Thermo-Calc software and the reported thermodynamic descriptions [25-29] are shown in Figure 1 . The prepared alloys are located in two-phase regions at $673 \mathrm{~K}$. The intermetallic compounds can be obviously observed in both as-cast and annealed alloys. More intermetallic compounds are observed to precipitate with RE addition. The morphology of the integranular phase strongly influences the overall properties of alloys [31].
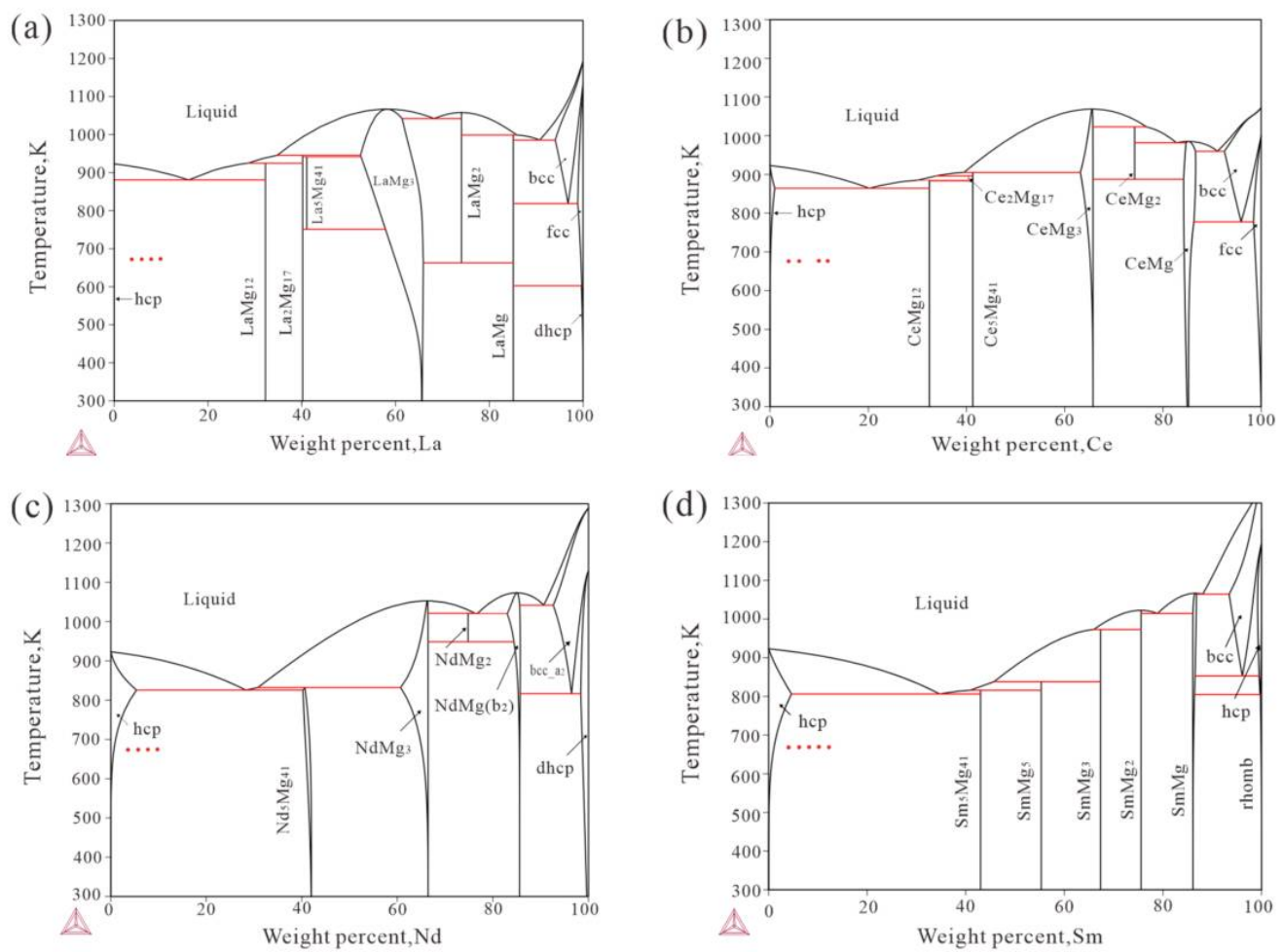

Figure 1. Phase diagram of: (a) the Mg-La system; (b) the Mg-Ce system; (c) the Mg-Nd system; (d) the Mg-Sm system.

\subsection{Mg-La Alloys}

Figure 2a-d show the back-scattered electron (BSE) images of Mg-La alloys. It shows that both the as-cast and annealed alloys consisted of $\alpha-\mathrm{Mg}$ phase and the intermetallic compound $\mathrm{LaMg}_{12}$. The $\mathrm{LaMg}_{12}$ phase appearing light-grey in Figure $2 \mathrm{a}$ almost fully surrounds the grains of $\alpha-\mathrm{Mg}$ phase appearing dark-grey, and separates them from each other. Such behavior is intimately connected with the complete and incomplete wetting of grain boundaries by the melt or second phase [3,32]. With La addition, more $\mathrm{LaMg}_{12}$ is precipitated. Besides this, a distinct dendritic morphology was observed in as-cast Mg-10La alloys with island-shaped $\alpha$-Mg separated by $\mathrm{LaMg}_{12}$, and the $\mathrm{LaMg}_{12}$ in the annealed Mg-10La alloy was evenly distributed. Therefore, the grain size was decreased. Figure 2e,f present the XRD patterns for phase identification. The results are consistent with the analysis by SEM. 

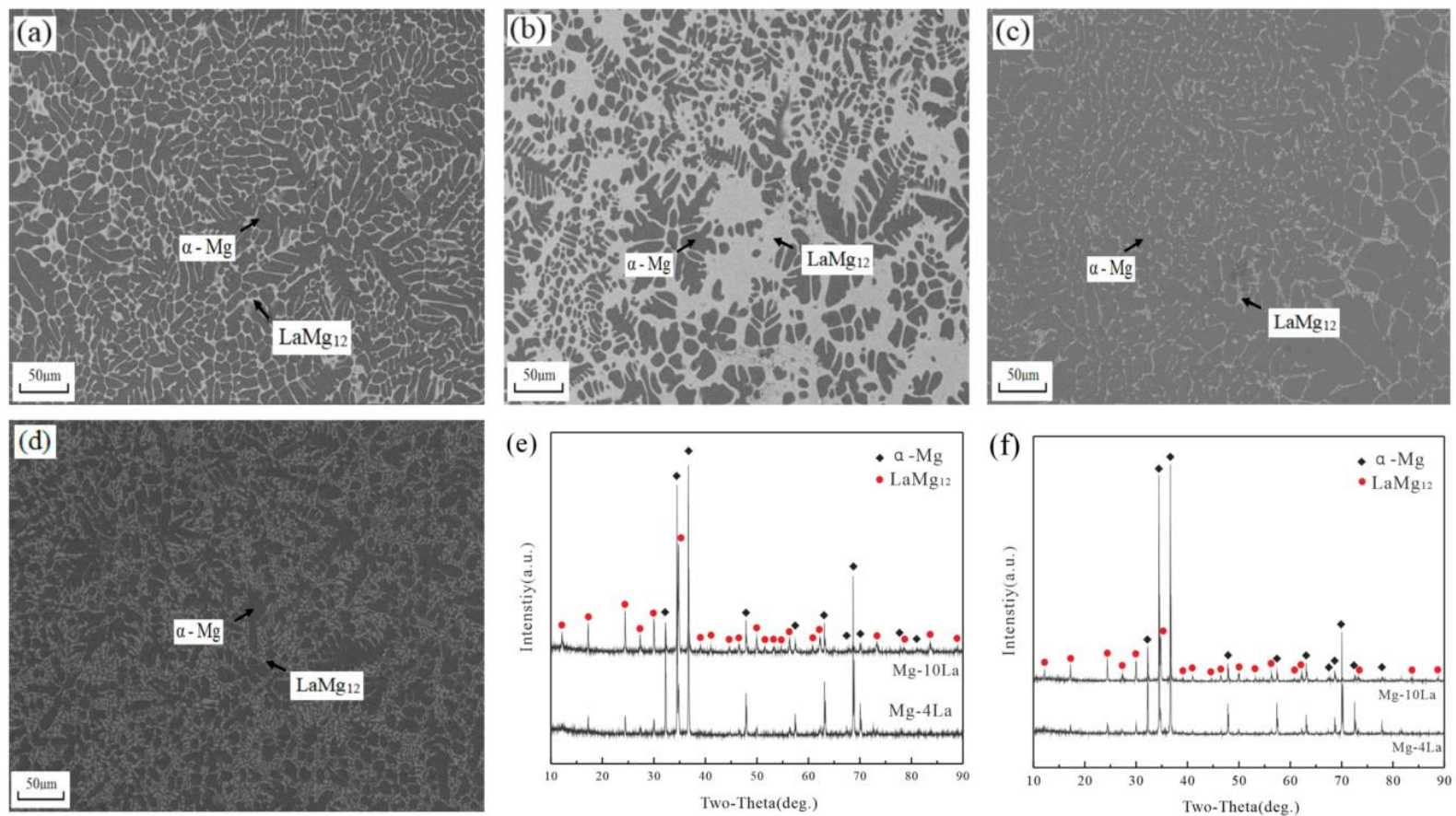

Figure 2. BSE micrographs of (a) the as-cast Mg-4La alloy, (b) the as-cast Mg-10La alloy, (c) the annealed Mg-4La alloy, and (d) the annealed Mg-10La alloy; and XRD diffraction patterns of (e) the as-cast Mg- $4 \mathrm{La}$ and Mg-10La alloys, and (f) the annealed Mg-4La and Mg-10La alloys.

It is observed from Figure 3 that thermal conductivity in two states decreased obviously after La was added. For as-cast alloy, it decreased from $127.699 \mathrm{~W} /(\mathrm{m} \times \mathrm{K})$ in Mg-4La alloy to $100.295 \mathrm{~W} /(\mathrm{m} \times \mathrm{K})$ in Mg-10La alloy at $298 \mathrm{~K}$. For the annealed alloy, it decreased from $133.748 \mathrm{~W} /(\mathrm{m} \times \mathrm{K})$ to $113.189 \mathrm{~W} /(\mathrm{m} \times \mathrm{K})$. Besides this, Figure 3a,b illustrate that the thermal conductivity in two states increased with temperature rise, which is contrary to the trend in pure magnesium measured by Hol et al. [33]. The thermal conductivities steadily rose in as-cast Mg-4La alloys from $127.699 \mathrm{~W} /(\mathrm{m} \times \mathrm{K})$ at $298 \mathrm{~K}$ to $135.127 \mathrm{~W} /(\mathrm{m} \times \mathrm{K})$ at $673 \mathrm{~K}$. As for the annealed alloy, it even reached $138.476 \mathrm{~W} /(\mathrm{m} \times \mathrm{K})$ at $673 \mathrm{~K}$. Consequently, the thermal conductivity increases at the same composition and temperature after homogenization annealing treatment.
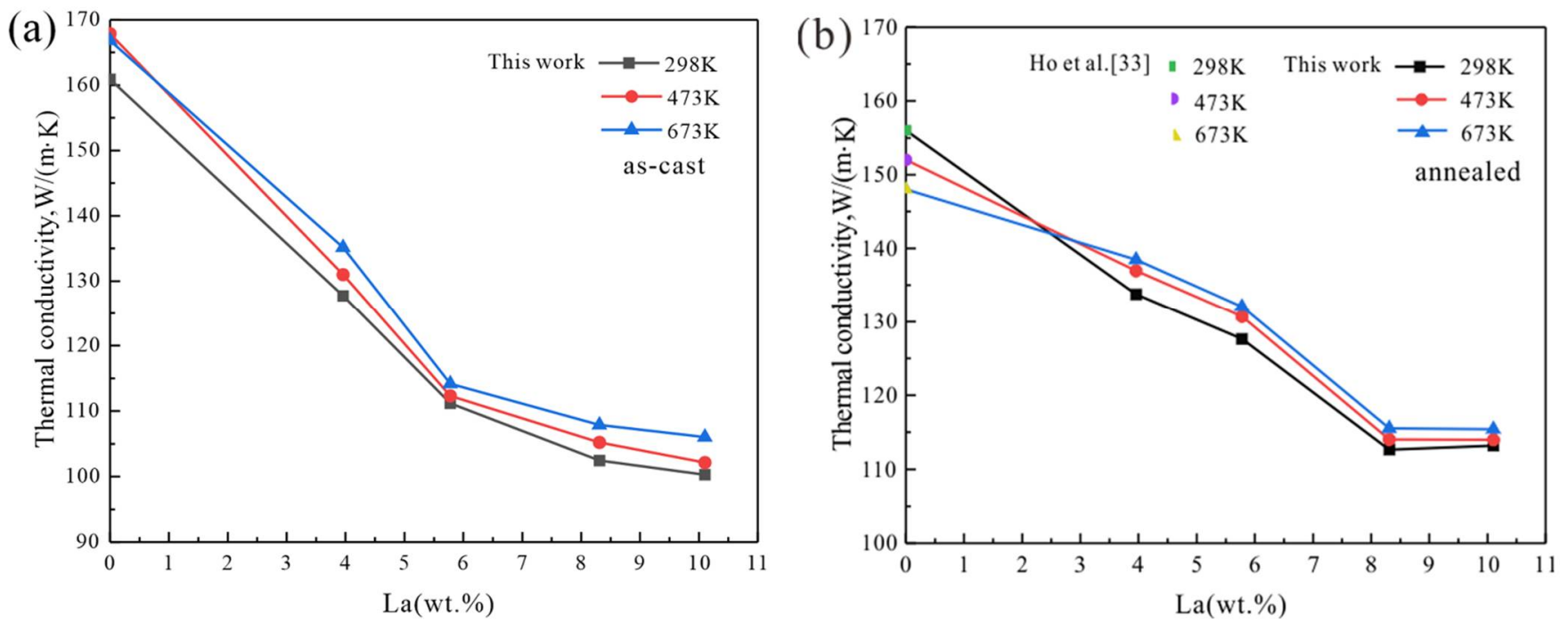

Figure 3. Thermal conductivity of (a) as-cast Mg-La alloys; (b) annealed Mg-La alloys. 


\section{2. $\mathrm{Mg}$-Ce Alloys}

As shown in Figure $4 \mathrm{a}-\mathrm{d}$, both $\alpha-\mathrm{Mg}$ phase and intermetallic compound $\mathrm{CeMg}_{12}$ were observed in the as-cast and annealed states in Mg-(4,12)Ce alloy. With the addition of $\mathrm{Ce}$, the amount of $\mathrm{CeMg}_{12}$ increased significantly. For as-cast alloys, the $\mathrm{CeMg}_{12}$ phase in $\mathrm{Mg}-4 \mathrm{Ce}$ alloy was continuously distributed in the network of $\alpha-\mathrm{Mg}$ matrix, while the $\alpha-\mathrm{Mg}$ matrix phase was completely separated by $\mathrm{CeMg}_{12}$ in the island shape and irregular distribution in $\mathrm{Mg}-12 \mathrm{Ce}$ alloy. For annealed alloys, $\mathrm{CeMg}_{12}$ in the $\mathrm{Mg}-4 \mathrm{Ce}$ alloy became a semi-continuous network, which was distributed in the $\alpha-\mathrm{Mg}$. The CeMg12 in the annealed $\mathrm{Mg}-12 \mathrm{Ce}$ alloy was evenly distributed and the grain size was decreased. Figure 4e,f show the XRD patterns, which confirm the observations by SEM.
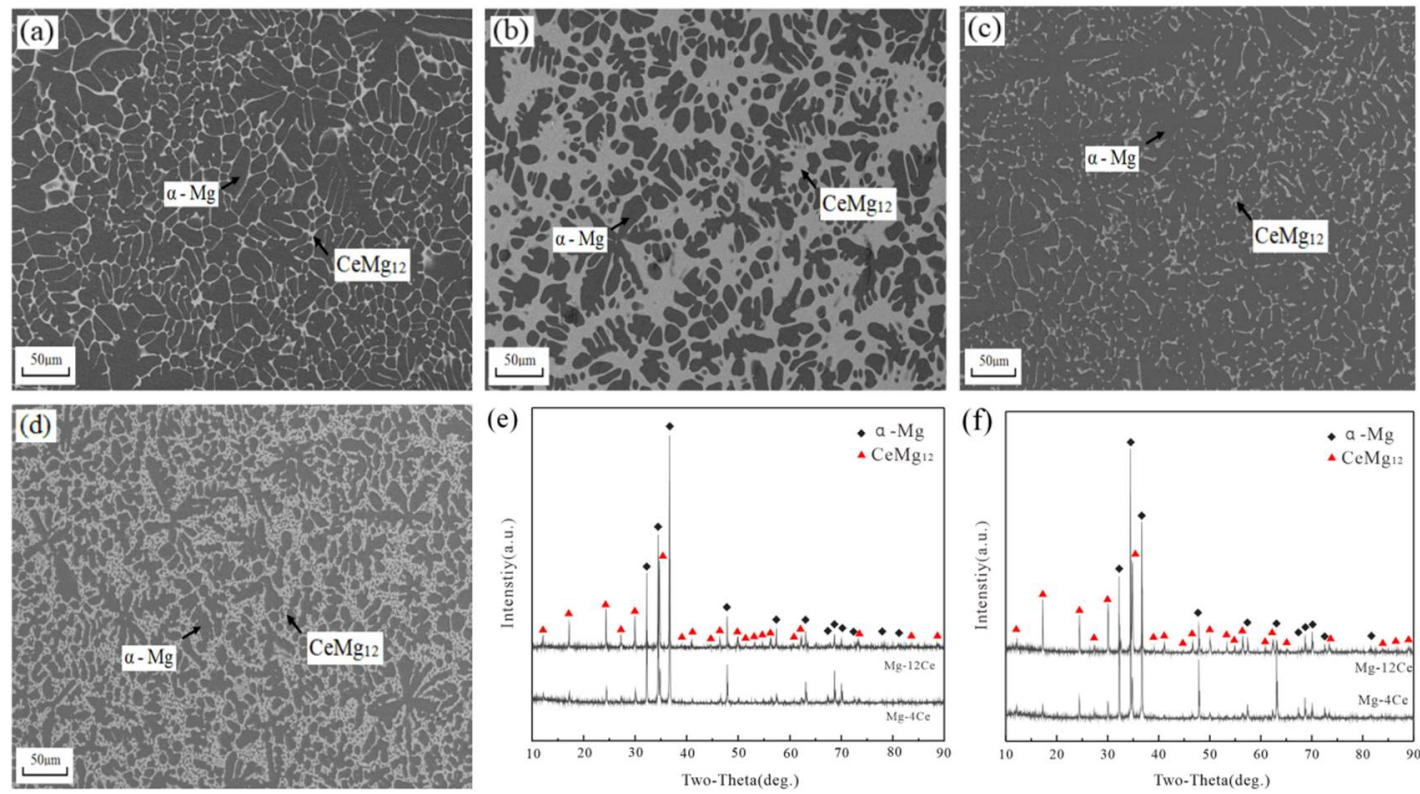

Figure 4. BSE micrographs of (a) the as-cast Mg-4Ce alloy, (b) the as-cast Mg-12Ce alloy, (c) the annealed Mg-4ce alloy, and (d) the annealed $\mathrm{Mg}-12 \mathrm{Ce}$ alloy; and XRD diffraction patterns of (e) the as-cast $\mathrm{Mg}-4 \mathrm{Ce}$ and $\mathrm{Mg}-12 \mathrm{Ce}$ alloys, and (f) the annealed Mg-4Ce and Mg-12Ce alloys.

Figure $5 \mathrm{a}, \mathrm{b}$ demonstrate that after Ce was added, the thermal conductivity in two states reduced dramatically. For as-cast alloy, it reached $118.298 \mathrm{~W} /(\mathrm{m} \times \mathrm{K})$ at $298 \mathrm{~K}$ in $\mathrm{Mg}-4 \mathrm{Ce}$ alloy, then it decreased to $91.986 \mathrm{~W} /(\mathrm{m} \times \mathrm{K})$ in $\mathrm{Mg}-12 \mathrm{Ce}$ alloy. In annealed state, it dropped from $137.031 \mathrm{~W} /(\mathrm{m} \times \mathrm{K})$ to $111.876 \mathrm{~W} /(\mathrm{m} \times \mathrm{K})$. Figure $5 \mathrm{a}, \mathrm{b}$ also illustrate that the thermal conductivity increased significantly with temperature rise at the same Ce content, which is different to the trend in pure magnesium. The value of thermal conductivity of the as-cast Mg-4Ce alloy reached $118.298 \mathrm{~W} /(\mathrm{m} \times \mathrm{K})$ at $298 \mathrm{~K}$, then it increased to $129.687 \mathrm{~W} /(\mathrm{m} \times \mathrm{K})$ at $673 \mathrm{~K}$. As for annealed Mg-4Ce alloy, it increased from $137.031 \mathrm{~W} /(\mathrm{m} \times \mathrm{K})$ to $143.129 \mathrm{~W} /(\mathrm{m} \times \mathrm{K})$. It also demonstrates that thermal conductivity increased at the same composition and temperature after homogenization annealing treatment.

\section{3. $M g-N d$ Alloys}

The BSE images are shown in Figure 6, where the metastable phase $\mathrm{NdMg}_{12}$ and stable phase $\mathrm{Nd}_{5} \mathrm{Mg}_{41}$ are observed in Figure $6 \mathrm{a}, \mathrm{b}$ and Figure $6 \mathrm{c}, \mathrm{d}$, respectively. Zhai et al. [34] found that rapid cooling of Mg-24 wt.\% Nd leads to the appearance of metastable phase. When the cooling rate is $14^{\circ} \mathrm{C} / \mathrm{min}$, the metastable phase $\mathrm{NdMg}_{12}$ forms. Stable phase $\mathrm{Nd}_{5} \mathrm{Mg}_{41}$ forms when the cooling rate decreases to $6{ }^{\circ} \mathrm{C} / \mathrm{min}$. In this experiment, metastable phase $\mathrm{NdMg}_{12}$ appeared in the as-cast alloys because of the excessive cooling rate. $\mathrm{NdMg}_{12}$ was distributed as semi-continuously region in the as-cast $\mathrm{Mg}-4 \mathrm{Nd}$ alloy. With $\mathrm{Nd}$ addition, more $\mathrm{NdMg}_{12}$ was observed to precipitate as shown in the as-cast 
Mg-10Nd alloy. The $\mathrm{NdMg}_{12}$ phase showed a network structure with inhomogeneous region. After homogenization treatment, $\mathrm{Nd}_{5} \mathrm{Mg}_{41}$ was distributed semi-continuously and regularly among the grains of $\alpha-\mathrm{Mg}$ in $\mathrm{Mg}-4 \mathrm{Nd}$ alloy. $\mathrm{Nd}_{5} \mathrm{Mg}_{41}$ appeared as a network and the grains gradually became coarser in the annealed Mg-10Nd alloy. Figure 6e,f show the XRD patterns, which confirms the phase constitution by SEM.

(a)

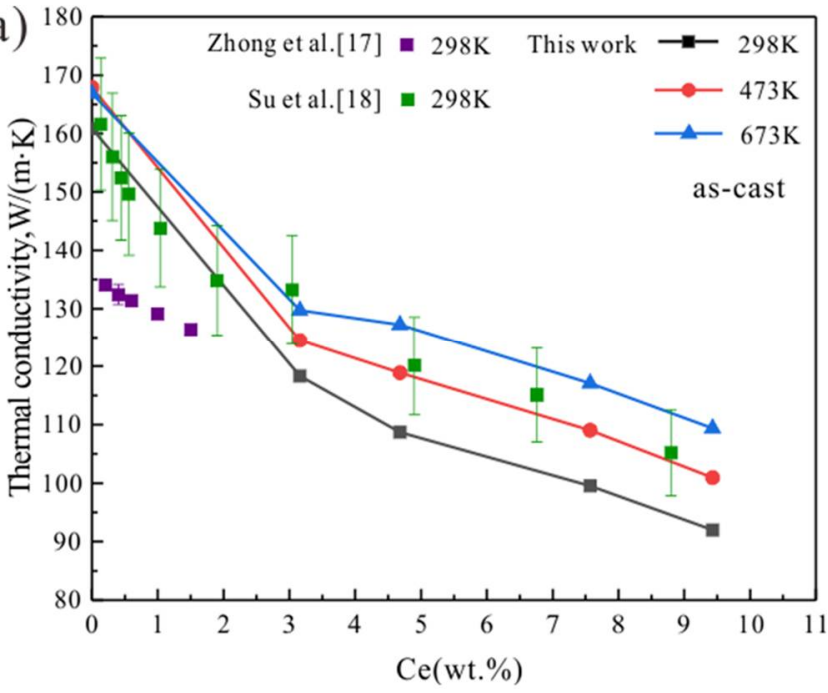

(b)

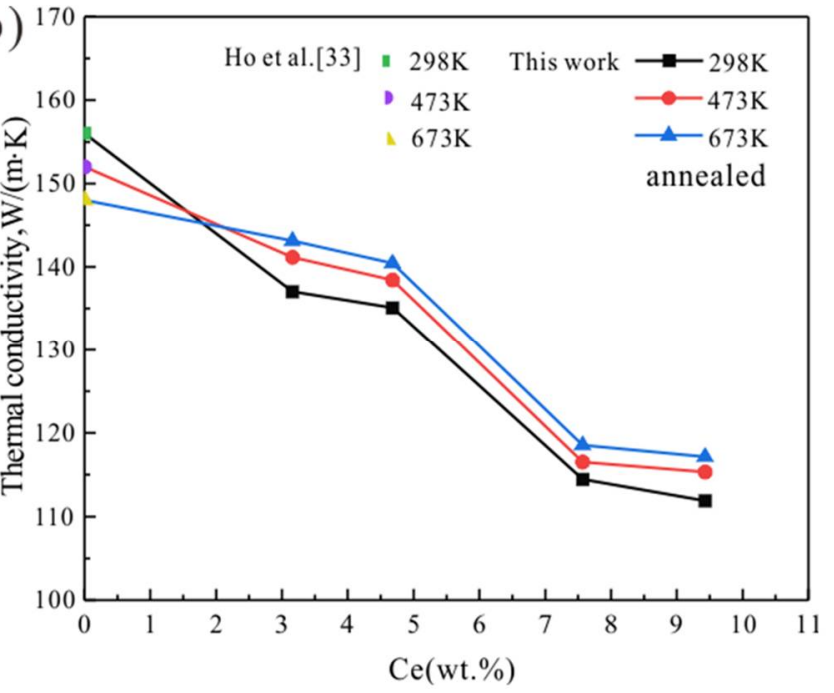

Figure 5. Thermal conductivity of (a) as-cast Mg-Ce alloys; (b) annealed Mg-Ce alloys.
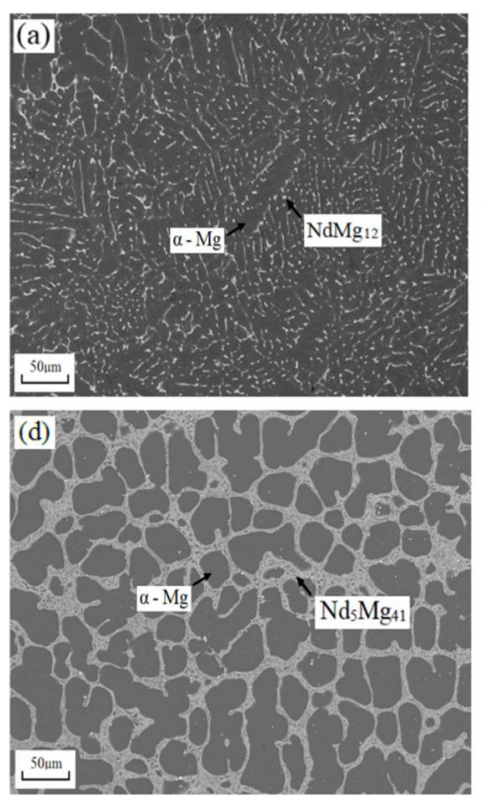
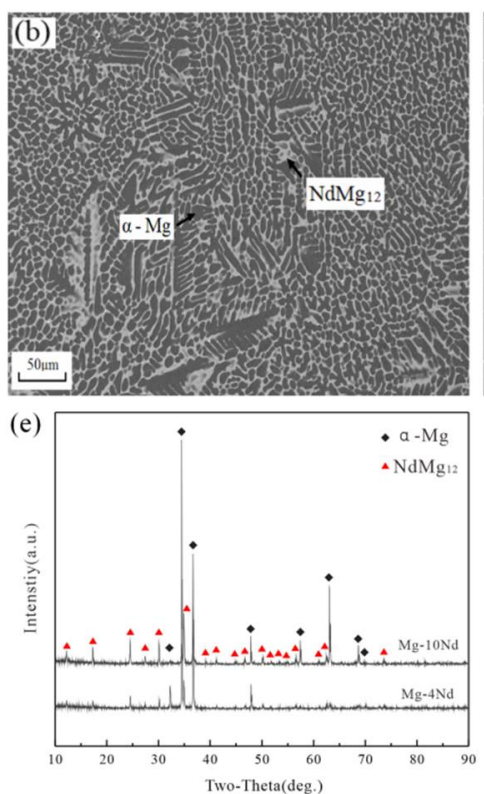
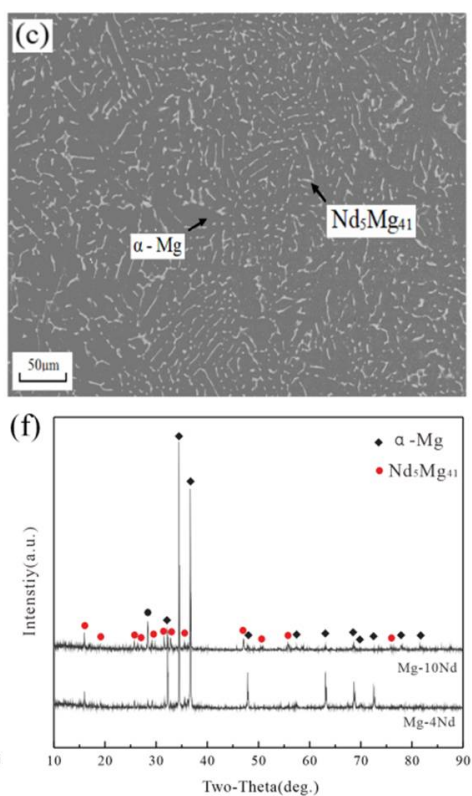

Figure 6. BSE micrographs of (a) the as-cast $\mathrm{Mg}-4 \mathrm{Nd}$ alloy, (b) the as-cast $\mathrm{Mg}-10 \mathrm{Nd}$ alloy, (c) the annealed $\mathrm{Mg}-4 \mathrm{Nd}$ alloy, and (d) the annealed $\mathrm{Mg}-10 \mathrm{Nd}$ alloy; and XRD diffraction patterns of (e) the as-cast $\mathrm{Mg}-4 \mathrm{Nd}$ and $\mathrm{Mg}-10 \mathrm{Nd}$ alloys, and (f) the annealed $\mathrm{Mg}-4 \mathrm{Nd}$ and $\mathrm{Mg}-10 \mathrm{Nd}$ alloys.

Figure $7 \mathrm{a}, \mathrm{b}$ illustrate that the thermal conductivity in the two states decreased almost linearly after $\mathrm{Nd}$ addition. The value of thermal conductivity reached $98.951 \mathrm{~W} /(\mathrm{m} \times \mathrm{K})$ in as-cast state for Mg-4Nd alloy at $298 \mathrm{~K}$, then it decreased to $66.291 \mathrm{~W} /(\mathrm{m} \times \mathrm{K})$ in $\mathrm{Mg}$ $10 \mathrm{Nd}$ alloy. In annealed state, it dropped from $117.084 \mathrm{~W} /(\mathrm{m} \times \mathrm{K})$ to $92.480 \mathrm{~W} /(\mathrm{m} \times \mathrm{K})$. Figure 7 also shows that the thermal conductivity increased significantly with temperature rise at the same $\mathrm{Nd}$ content, which is inconsistent with the pure magnesium. The value of thermal conductivity of as-cast Mg- $4 \mathrm{Nd}$ alloy reached $98.951 \mathrm{~W} /(\mathrm{m} \times \mathrm{K})$ at $298 \mathrm{~K}$, then it increased obviously to $135.981 \mathrm{~W} /(\mathrm{m} \times \mathrm{K})$ at $673 \mathrm{~K}$. Meanwhile, in annealed Mg- 
$4 \mathrm{Nd}$ alloy, it increased from $117.084 \mathrm{~W} /(\mathrm{m} \times \mathrm{K})$ to $133.436 \mathrm{~W} /(\mathrm{m} \times \mathrm{K})$. So, the thermal conductivity increased at the same composition and temperature after homogenization annealing treatment.

(a)

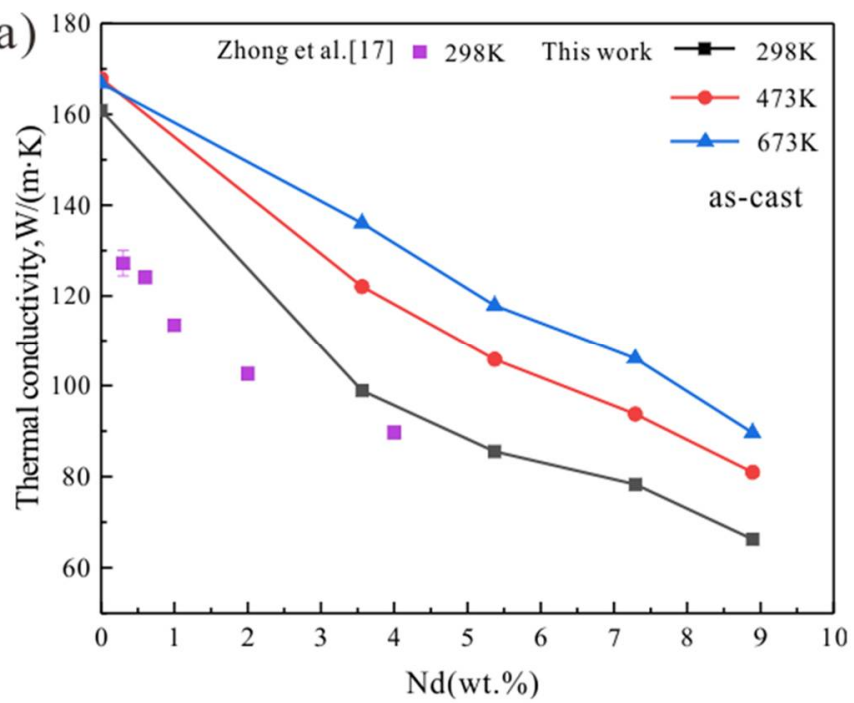

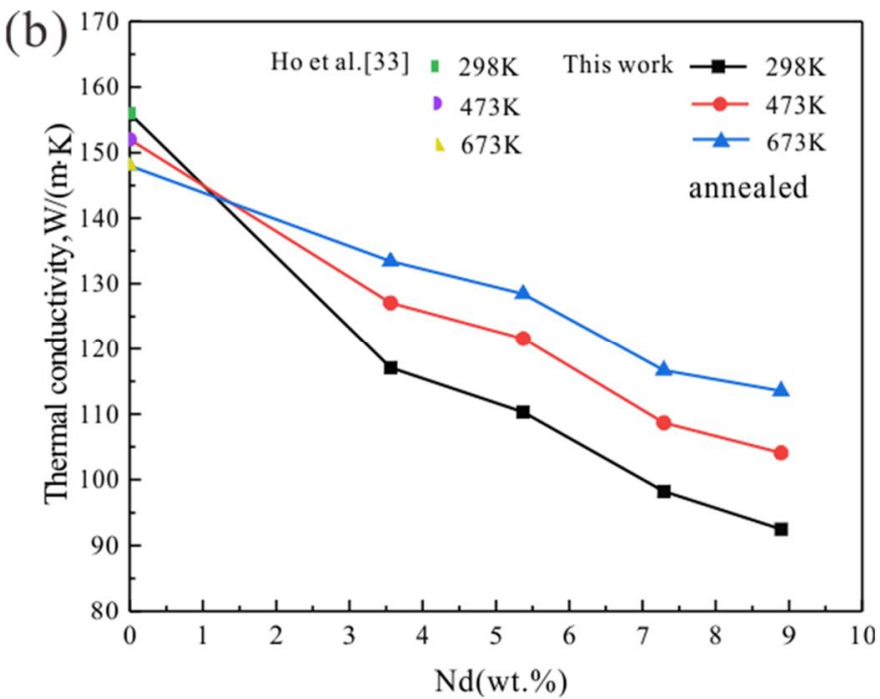

Figure 7. Thermal conductivity of (a) as-cast Mg-Nd alloys; (b) annealed Mg-Nd alloys.

\section{4. $M g$-Sm Alloys}

Figure 8a-d show the BSE images of Mg-Sm alloys, where the $\alpha-\mathrm{Mg}$ phase and intermetallic compound $\mathrm{Sm}_{5} \mathrm{Mg}_{41}$ are observed. With Sm addition, more $\mathrm{Sm}_{5} \mathrm{Mg}_{41}$ is observed to precipitate in the matrix phase. For as-cast alloys, $\mathrm{Sm}_{5} \mathrm{Mg}_{41}$ in a parallel plank shape uniformly separated the $\alpha-\mathrm{Mg}$ in the Mg-4Sm alloy, while the morphology of the $\mathrm{Sm}_{5} \mathrm{Mg}_{41}$ in the $\mathrm{Mg}-12 \mathrm{Sm}$ alloy showed the microstructure of fish-bone shape. After homogenization treatment, a small amount of the $\mathrm{Sm}_{5} \mathrm{Mg}_{41}$ was discontinuously distributed between the $\alpha-\mathrm{Mg}$ phase. Meanwhile, the fish-bone shape structure observed from the BSE images of the as-cast alloy were transformed into a coarse network structure in annealed Mg-12Sm alloy. XRD patterns of Mg-Sm alloys are presented in Figure 8e,f; the second phase of alloys in two states is $\mathrm{Sm}_{5} \mathrm{Mg}_{41}$, which is consistent with the result by SEM.

The addition of Sm linearly decreased the thermal conductivity of Mg-Sm alloys as illustrated in Figure 9. For as-cast alloys, thermal conductivity reached $83.398 \mathrm{~W} /(\mathrm{m} \times \mathrm{K})$ in Mg-4Sm alloy at $298 \mathrm{~K}$, then it decreased to $58.404 \mathrm{~W} /(\mathrm{m} \times \mathrm{K})$ in $\mathrm{Mg}-12 \mathrm{Sm}$ alloy. For annealed alloys, it dropped from $99.875 \mathrm{~W} /(\mathrm{m} \times \mathrm{K})$ to $81.075 \mathrm{~W} /(\mathrm{m} \times \mathrm{K})$. Additionally, Figure 9 shows that the thermal conductivity increased significantly with temperature rise at the same Sm content, which is inconsistent with the pure magnesium. The value of thermal conductivity increased from $83.398 \mathrm{~W} /(\mathrm{m} \times \mathrm{K})$ at $298 \mathrm{~K}$ to $116.464 \mathrm{~W} /(\mathrm{m} \times \mathrm{K})$ at $673 \mathrm{~K}$ in as-cast state for $\mathrm{Mg}-4 \mathrm{Sm}$ alloy. For annealed $\mathrm{Mg}-4 \mathrm{Sm}$ alloy, it increased from $99.875 \mathrm{~W} /(\mathrm{m} \times \mathrm{K})$ to $127.367 \mathrm{~W} /(\mathrm{m} \times \mathrm{K})$. It also demonstrates that thermal conductivity increased at the same composition and temperature after the homogenization annealing treatment. 

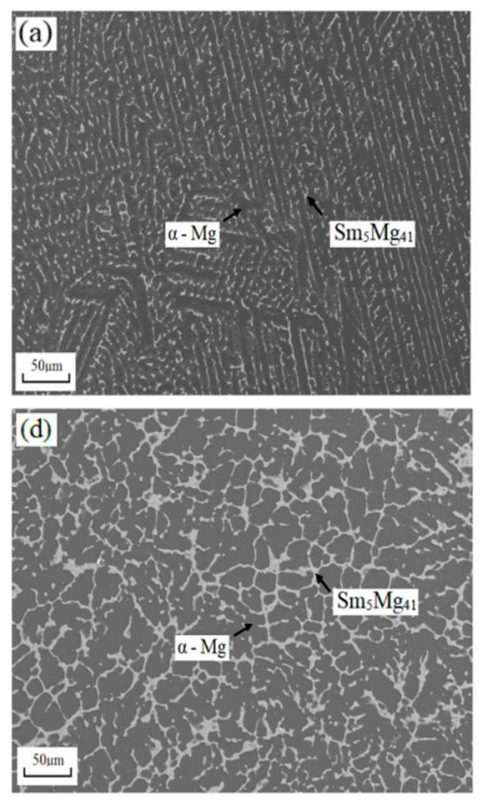
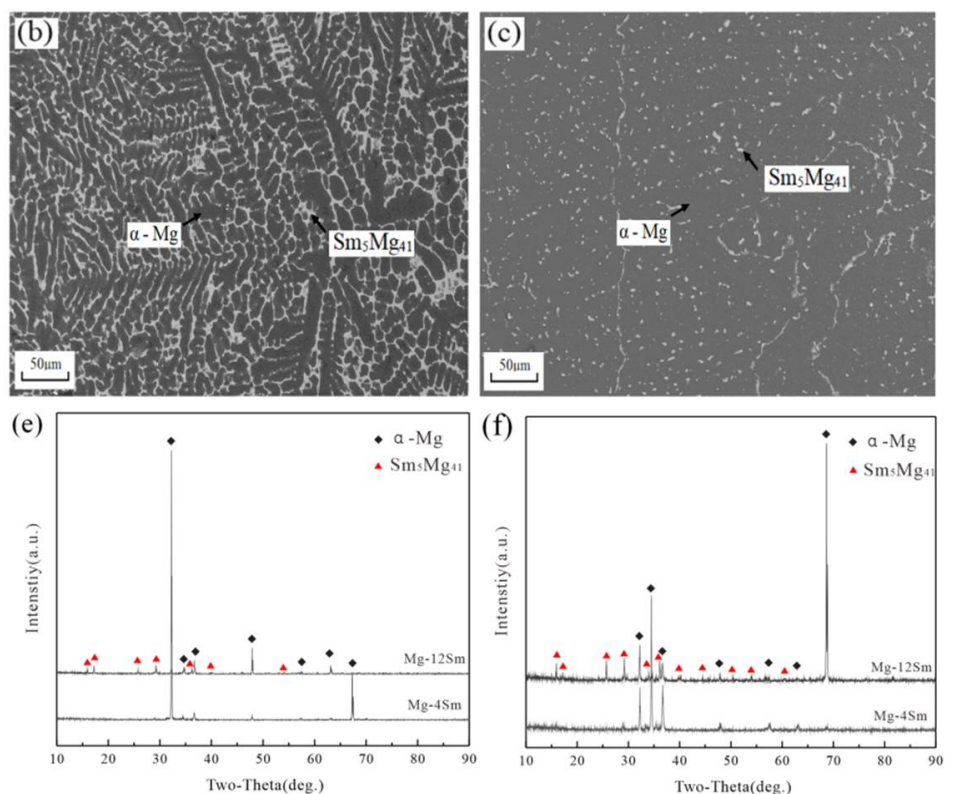

Figure 8. BSE micrographs of (a) the as-cast Mg-4Sm alloy, (b) the as-cast $\mathrm{Mg}-12 \mathrm{Sm}$ alloy, (c) the annealed Mg- $4 \mathrm{Sm}$ alloy, and (d) the annealed $\mathrm{Mg}-12 \mathrm{Sm}$ alloy; and XRD diffraction patterns of (e) the as-cast $\mathrm{Mg}-4 \mathrm{Sm}$ and $\mathrm{Mg}-12 \mathrm{Sm}$ alloys, and (f) the annealed $\mathrm{Mg}-4 \mathrm{Sm}$ and $\mathrm{Mg}-12 \mathrm{Sm}$ alloys.
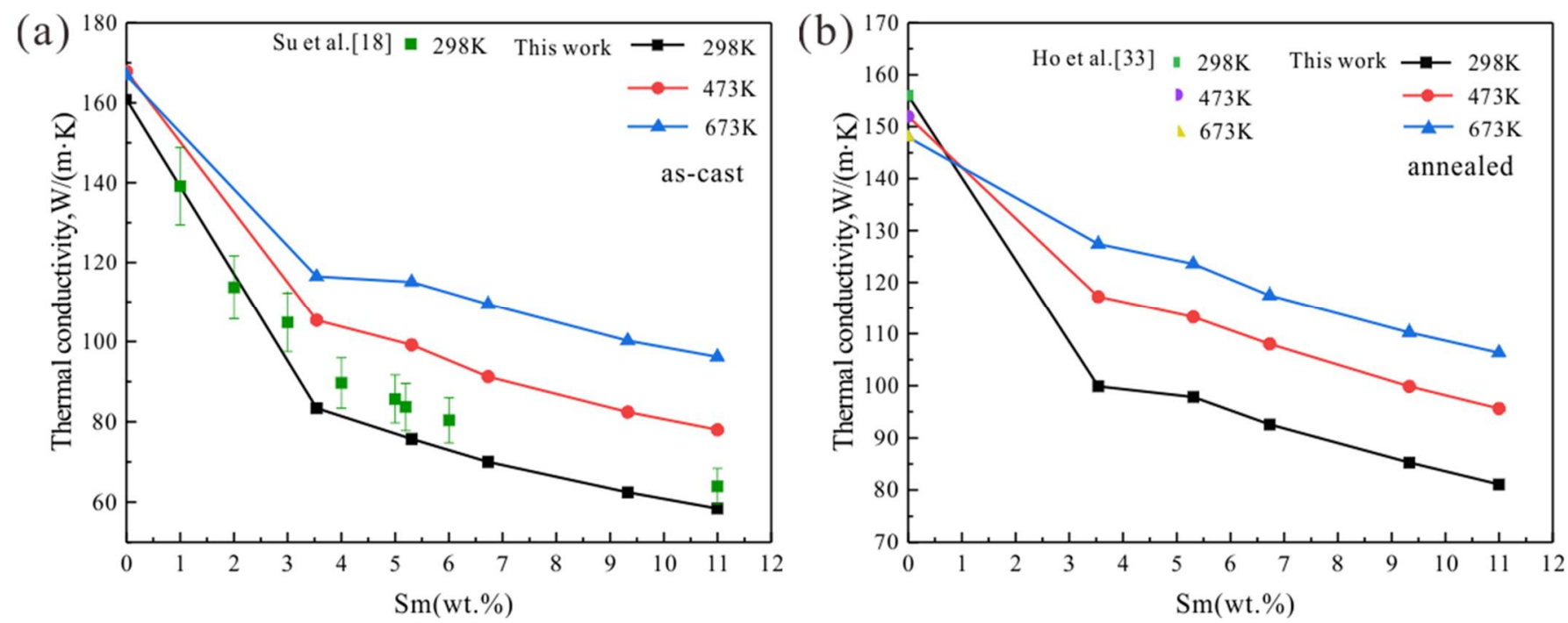

Figure 9. Thermal conductivity of (a) as-cast Mg-Sm alloys; (b) annealed Mg-Sm alloys.

\section{Discussion}

\subsection{Temperature Dependence}

Ho et al. [33] measured the thermal conductivity of pure magnesium from 1 to $700 \mathrm{~K}$, and extrapolated it at the temperature range between 773.2 and $923.2 \mathrm{~K}$. It was found that thermal conductivity increased sharply from 1 to $9 \mathrm{~K}$, and reached the maximum value of $5700 \mathrm{~W} /(\mathrm{m} \times \mathrm{K})$ at $9 \mathrm{~K}$, then sharply dropped to $169 \mathrm{~W} /(\mathrm{m} \times \mathrm{K})$ at $100 \mathrm{~K}$. When the temperature was higher than $100 \mathrm{~K}$, the thermal conductivity decreased slowly. The temperature range selected in this experiment, the thermal conductivity of pure magnesium reduced slowly with temperature rise.

In this study, although the RE atoms in $\alpha-\mathrm{Mg}$ acted as impurities after RE elements were added, there was no temperature dependence of the electrical resistance caused by impurities [35]. Besides this, the number and energy of phonons rose greatly with 
the increasing temperature, and lattice vibration became stronger, which hindered its free movement, so the thermal conductivity caused by the phonons decreased. The heat of many metals at ambient temperature is conducted by electrons [36]. The thermal conductivity caused by electrons plays a dominant role in the alloy. The WiedemannFranz law indicates that the thermal conductivity caused by electrons increases with the increasing temperature. Consequently, the thermal conductivity of Mg-RE alloys increases with increasing temperature. Figure $3 b$, Figure $5 b$, Figure $7 b$, and Figure $9 b$ compare the thermal conductivity of pure magnesium and alloy. In pure magnesium, the thermal conductivity decreased with increasing temperature. Therefore, the lines of the relationship between thermal conductivity and temperature shown in the above figures are crossed.

\subsection{Effect of Homogenization Treatment}

The electron conduction is limited by the impurities scattering process, and the scattering of impurities is affected by its own thermal resistance and lattice defects [36]. On the one hand, homogenization treatment can reduce the lattice defects produced during the casting process. It also reduces the scattering of impurities and thermal resistance. Then, it increases the conduction of electrons, whereby the thermal conductivity of the $\mathrm{Mg}$-RE alloys rises. On the other hand, for the Mg-Nd system with the metastable phase $\mathrm{Nd}_{12} \mathrm{Mg}$, the metastable precipitation phase transformed into the stable phase $\mathrm{Nd}_{5} \mathrm{Mg}_{41}$ after homogenization treatment. The solute atoms precipitate and reduce the distortion of lattice and intensify the free movement of electrons and phonons, which increase the thermal conductivity. In this experiment, homogenization annealing treatment increased the thermal conductivity.

\subsection{Effect of RE Elements}

Figure 10a,b show the influence of the thermal conductivity of the RE elements addition in pure magnesium. With RE addition, RE atoms were dissolved in $\alpha$-Mg matrix phase. $\mathrm{RE}$ atoms that are dissolved in $\alpha$-Mg destroy periodic arrangement of magnesium lattice, which causes lattice distortion. Consequently, the thermal conductivity decreases. The BSE images indicate that the content of intermetallic compounds increases significantly with the increase of RE content. These two factors cause the decrease of thermal conductivity. In addition, the slope of the lines reflects the decrease levels of thermal conductivity. After adding $\mathrm{Nd}$ and $\mathrm{Sm}$, which show observable solid solubility in $\alpha-\mathrm{Mg}$, the levels of the reduction of thermal conductivity are significantly greater than adding La and Ce with negligible solid solubility in $\alpha-\mathrm{Mg}$.
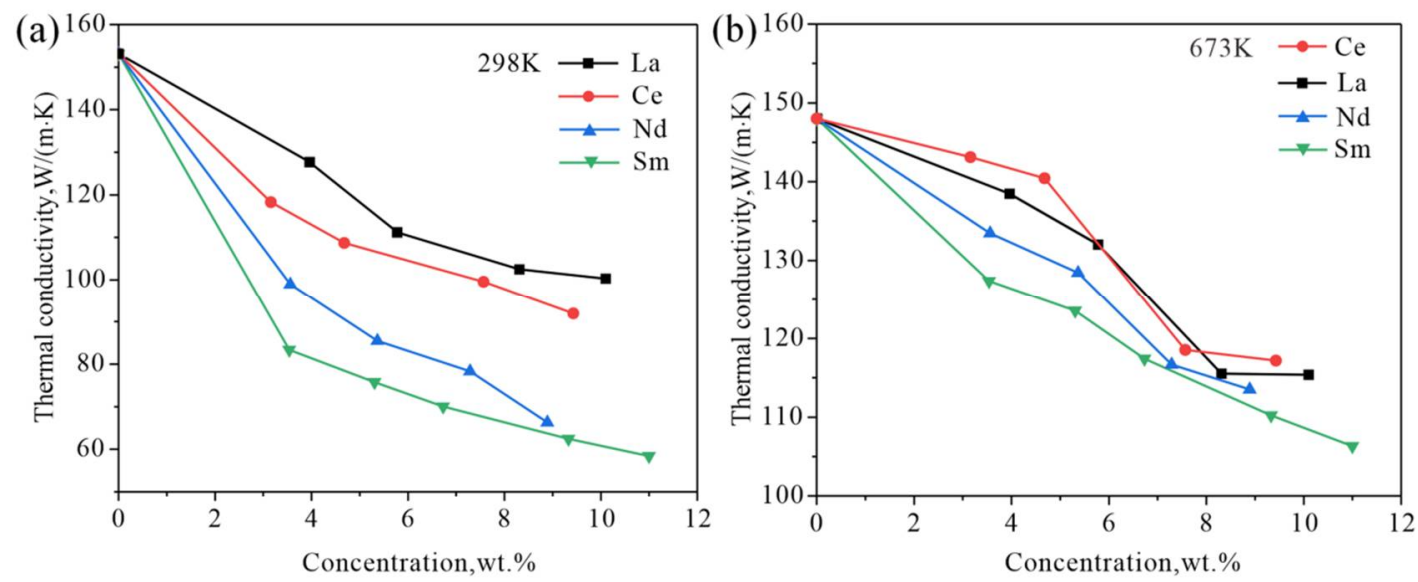

Figure 10. Effect of alloying elements addition on thermal conductivity of (a) as-cast magnesium alloys at 298 K; (b) annealed magnesium alloys at $673 \mathrm{~K}$.

The valence also affects the thermal conductivity. Table 2 shows that the valence number of the four RE atoms is 3, and the valence number of magnesium atoms is 2 . The 
lattice expands after the RE atom is dissolved in $\alpha-\mathrm{Mg}$. This phenomenon is affected by the following two factors: the electronic structure of magnesium and the shape of the Brillouin zone $[14,37]$. That is to say, the effects of valence of four elements are similar.

Table 2. Atomic number, valence, atomic radius and maximum solid solubility in the $\mathrm{Mg}$ solid solution of the four solute atoms.

\begin{tabular}{ccccc}
\hline Element & Atomic Number & Valence & Atomic Radius/nm & $\begin{array}{c}\text { Maximum Solid Solubility } \\
\text { wt.\%/at.\% in Mg }\end{array}$ \\
\hline $\mathrm{Mg}$ & 12 & +2 & 0.1602 & - \\
$\mathrm{La}$ & 57 & +3 & 0.1877 & $5.55 \times 10^{-7} \approx 0$ \\
$\mathrm{Ce}$ & 58 & +3 & 0.1824 & $0.52 / 0.09$ \\
$\mathrm{Nd}$ & 60 & +3 & 0.1821 & $3.63 / 0.63$ \\
$\mathrm{Sm}$ & 62 & +3 & 0.1804 & $5.83 / 0.99$ \\
\hline
\end{tabular}

Thermal conductivity is affected by atomic radius. The RE atoms were dissolved in $\alpha-\mathrm{Mg}$ to form a substitutional solid solution, leading to the lattice distortion. The larger the difference of atoms between the RE atoms and the magnesium atoms, the more serious the lattice distortion [14]. That reduces the thermal conductivity. It can be seen from Table 2 that the effect of atomic radius is: $\mathrm{La}>\mathrm{Ce}>\mathrm{Nd}>\mathrm{Sm}$.

In this experiment, the solid solution reached saturation after RE elements were added. Eivani et al. [38] show that, compared with the second phase, the solid solubility has more negative effect on thermal conductivity. The solid solubility of solute atoms in $\alpha-\mathrm{Mg}$ is affected by the radius difference between RE atoms and magnesium atoms. The radius difference between $\mathrm{Sm}$ atoms and magnesium atoms is the smallest, and the solid solubility is the largest. Table 2 shows the maximum solid solubility of four RE atoms. The influence of solid solubility is: $\mathrm{Sm}>\mathrm{Nd}>\mathrm{Ce}>\mathrm{La}$.

Adding variety of RE elements into magnesium alloy, its thermal conductivity is affected by factors such as atomic radius, solid solubility, and valence. This study has found that the solid solubility among the above factors plays a dominant role in the thermal conductivity of Mg-RE binary alloy.

\section{Conclusions}

(1) Thermal conductivity of the studied Mg-RE alloys decreases with RE addition, and increases with increasing temperature.

(2) The annealed Mg-RE alloys featured higher thermal conductivity than the as-cast alloys at the same composition and temperature. Homogenization treatment can increase the thermal conductivity.

(3) The solid solubility of Sm in $\alpha-\mathrm{Mg}$ is the largest, and Mg-Sm alloy has the lowest thermal conductivity under the same conditions. The reduction of thermal conductivity caused by the addition of $\mathrm{Nd}$ and $\mathrm{Sm}$, which show observable solid solubility in $\alpha-\mathrm{Mg}$, is significantly greater than the addition of La and Ce with negligible solid solubility in $\alpha-\mathrm{Mg}$.

Author Contributions: Funding acquisition, Y.D. and M.C.; investigation, H.G.; methodology, S.L.; supervision, S.L.; writing—original draft preparation, H.G., L.H. and D.W.; writing—review and editing, S.L. All authors have read and agreed to the published version of the manuscript.

Funding: This work was supported by the National Key Research and Development Program of China (No. 2016YFB0701202). The Program for Guangdong Introducing Innovative and Entrepreneurial Teams (No. 2016ZT06G025) and Guangdong Natural Science Foundation (No. 2017B030306014) are acknowledged.

Conflicts of Interest: The authors declare no conflict of interest. 


\section{References}

1. Imandoust, A.; Barrett, C.D.; Al-Samman, T.; Inal, K.A.; EI Kadiri, H. A review on the effect of rare-earth elements on texture evolution during processing of magnesium alloys. J. Mater. Sci. 2016, 52, 1-29. [CrossRef]

2. Suh, B.C.; Sasaki, T.; Nakata, T.; Kamado, S.; Hono, K. Effect of Ca on the microstructure, texture and mechanical properties in Mg-Zn-Mn based alloy. Magnes. Technol. 2017, 525-531. [CrossRef]

3. Straumal, A.; Mazilkin, I.; Tzoy, K.; Straumal, B.; Bryła, K.; Baranchikov, A.; Eggeler, G. Bulk and Surface Low Temperature Phase Transitions in the Mg-Alloy EZ33A. Metals 2020, 10, 1127. [CrossRef]

4. Rudajevová, A.; Buch, F.V.; Mordike, B.L. Thermal diffusivity and thermal conductivity of MgSc alloys. J. Alloys Compd. 1999, 292, 27-30. [CrossRef]

5. Zhang, C.; Du, Y.; Liu, S.H.; Liu, Y.L.; Sundman, B. Thermal conductivity of the Al-Cu-Mg-Si alloys: Experimental measurement and CALPHAD modeling. Thermochim. Acta 2016, 635, 8-16. [CrossRef]

6. Terada, Y.; Ohkubo, K.; Nakagawa, K.; Mohri, T.; Suzuki, T. Thermal conductivity of B2-type aluminides and titanides. Intermetallics 1995, 3, 347-355. [CrossRef]

7. Peet, M.J.; Hasan, H.S.; Bhadeshia, H. Prediction of thermal conductivity of steel. Int. J. Heat Mass Tran. 2011, 54, 2602-2608 [CrossRef]

8. Risegari, L.; Barucci, M.; Olivieri, E.; Pasca, E.; Ventura, G. Measurement of the thermal conductivity of copper samples between 30 and $150 \mathrm{mK}$. Cryogenics 2004, 44, 875-878. [CrossRef]

9. Yang, W.S.; Xiu, Z.Y.; Chen, G.Q.; Wu, G.H. Microstructure and thermal conductivity of submicron Si3N4 reinforced 2024Al composite. Trans. Nonferrous Met. Soc. China 2009, 19, 378-381. [CrossRef]

10. Gao, X.; Nie, J.F. Structure and thermal stability of primary intermetallic particles in an Mg-Zn casting alloy. Scr. Mater. 2007, 57, 655-658. [CrossRef]

11. Yamasaki, M.; Kagao, S.; Kawamura, Y.; Yoshimura, K. Thermal diffusivity and conductivity of supercooled liquid in Zr41Ti14Cu12Ni10Be23 metallic glass. Appl. Phys. Lett. 2004, 84, 4653-4655. [CrossRef]

12. Salter, J.A.M.; Charsley, P. The effect of grain size on the lattice thermal conductivity of copper aluminium alloys. Phys. Stat. Sol. 1967, 21, 357-368. [CrossRef]

13. Pan, H.; Pan, F.; Yang, R.; Peng, J.; Zhao, C.; She, J.; Gao, Z.; Tang, A. Thermal and electrical conductivity of binary magnesium alloys. J. Mater. Sci. 2014, 49, 3107-3124. [CrossRef]

14. Lyu, S.Y.; Li, G.D.; Hu, T.; Zheng, R.X.; Xiao, W.L.; Ma, C.L. A new cast Mg-Y-Sm-Zn-Zr alloy with high hardness. Mater. Lett. 2018, 217, 79-82. [CrossRef]

15. Zhang, Y.C.; Yang, L.; Dai, J.; Guo, G.L.; Liu, Z. Effect of Ca and Sr on microstructure and compressive creep property of Mg-4Al-RE alloys. Mater. Sci. Eng. A 2014, 610, 309-314. [CrossRef]

16. Wang, J.F.; Li, Y.; Huang, S.; Wei, Y.Y.; Xi, X.F.; Cai, K.Y.; Pan, F.S. Effects of Y on the microstructure, mechanical and bio-corrosion properties of Mg-Zn-Ca bulk metallic glass. J. Mater. Sci. Technol. 2014, 30, 1255-1261. [CrossRef]

17. Zhong, L.P.; Peng, J.; Sun, S.; Wang, Y.J.; Lu, Y.; Pan, F.S. Microstructure and thermal conductivity of as-cast and as-solutionized Mg-Rare earth binary Alloys. J. Mater. Sci. Technol. 2017, 33, 1240-1248. [CrossRef]

18. Su, C.Y.; Li, D.J.; Luo, A.A.; Ying, T.; Zeng, X.Q. Effect of solute atoms and second phases on the thermal conductivity of Mg-RE alloys: A quantitative study. J. Alloys Compd. 2018, 747, 431-437. [CrossRef]

19. Peng, J.; Zhong, L.P.; Wang, Y.J.; Lu, Y.; Pan, F.S. Effect of extrusion temperature on the microstructure and thermal conductivity of Mg-2.0Zn-1.0Mn-0.2Ce alloys. Mater. Des. 2015, 87, 914-919. [CrossRef]

20. Zhong, L.P.; Peng, J.; Li, M.; Wang, Y.J.; Lu, Y.; Pan, F.S. Effect of Ce addition on the microstructure, thermal conductivity and mechanical properties of Mg-0.5Mn alloys. J. Alloys Compd. 2016, 661, 402-410. [CrossRef]

21. Mills, K.C. Recommended values of thermophysical properties for selected commercial alloys. Aircr. Eng. Aerosp. Technol. 2002, 74, 492-494.

22. Touloukian, Y.S.; Buyco, E.H. Specific heat-metallic elements and alloys. In Thermophysical Properties of Matter-The TPRC Data Series; Touloukian, Y.S., Ho, C.Y., Eds.; Plenum Publishing Corp: New York, NY, USA, 1970; Volume 4, pp. 1-740.

23. Leitner, J.; Voňka, P.; Sedmidubský, D.; Svoboda, P. Application of Neumann-Kopp rule for the estimation of heat capacity of mixed oxides. Thermochim. Acta 2010, 497, 7-13. [CrossRef]

24. Rudajevová, A.; Lukác, P. Comparison of the thermal properties of AM20 and AS21 magnesium alloys. Mater. Sci. Eng. A 2005, 397, 16-21. [CrossRef]

25. Du, Y.; Liu, S.H.; Zhang, L.J.; Xu, H.H.; Zhao, D.D.; Wang, A.J. An overview on phase equilibria and thermodynamic modeling in multicomponent Al alloys: Focusing on the Al-Cu-Fe-Mg-Mn-Ni-Si-Zn system. Calphad 2011, 35, 427-445. [CrossRef]

26. Guo, C.P.; Du, Z.M.; Li, C.R. A thermodynamic description of the Ce-La-Mg system. Int. J. Mater. Res. 2010, 101, 1424-1431. [CrossRef]

27. Zhang, F.; Liu, S.H.; Du, Y. Experimental investigation and thermodynamic modeling of the La-Mg system. J. Alloys Compd. 2016, 663, 279-288. [CrossRef]

28. Qi, H.Y.; Huang, G.X.; Bo, H.; Xu, G.L.; Liu, L.B.; Jin, Z.P. Thermodynamic description of the Mg-Nd-Zn ternary system. J. Alloys Compd. 2011, 509, 3274-3281. [CrossRef]

29. Guo, C.P.; Du, Z.M.; Li, C.R. A thermodynamic description of the Gd-Mg-Sm system. Calphad 2010, 34, 90-97. [CrossRef]

30. Blumm, J. Measuring thermal conductivity. Ceram. Ind. 2002, 152, 53-59. 
31. Konyashin, I.; Lachmann, F.; Ries, B.; Mazilkin, A.A.; Straumal, B.B.; Kübel, C.; Llanes, L.; Baretzky, B. Strengthening zones in the Co matrix of WC-Co cemented carbides. Scr. Mater. 2014, 83, 17-20. [CrossRef]

32. Mazilkin, I.; Tsoy, K.; Straumal, A.; Rodin, A.; Baretzky, B. Grain boundary wetting of different types of grain boundaries in the Cu-Ag system. Mater. Lett. 2020, 272, 127730. [CrossRef]

33. Ho, C.Y.; Powell, R.W.; Liley, P.E. Thermal conductivity of the elements: A comprehensive review. J. Phys. Chem. Ref. Data 1974, 1 , $1-796$.

34. Zhai, C.; Luo, Q.; Cai, Q.; Guan, R.G.; Li, Q. Thermodynamically analyzing the formation of Mg12Nd and Mg41Nd5 in Mg-Nd system under a static magnetic field. J. Alloys Compd. 2019, 773, 202-209. [CrossRef]

35. Huang, L.; Liu, S.H.; Du, Y.; Zhang, C. Thermal conductivity of the Mg-Al-Zn alloys: Experimental measurement and CALPHAD modeling. Calphad 2018, 62, 99-108. [CrossRef]

36. White, G.K. The thermal conductivity of gold at low temperatures. Proc. Phys. Soc. Sect. A 1953, 66, 559-564. [CrossRef]

37. Ying, T.; Chi, H.; Zheng, M.; Li, Z.T.; Uher, C. Low-temperature electrical resistivity and thermal conductivity of binary magnesium alloys. Acta. Mater. 2014, 80, 288-295. [CrossRef]

38. Eivani, A.R.; Ahmed, H.; Zhou, J.; Duszczyk, J. Correlation between electrical resistivity, particle dissolution, precipitation of dispersoids, and recrystallization behavior of AA7020 aluminum alloy. Metall. Mater. Trans. 2009, 40, 2435-2446. [CrossRef] 